\title{
Microgeographical differentiation between morphotypes of Trididemnum orbiculatum (Tunicata: Ascidiacea) in southeastern Brazil
}

\author{
Gustavo Muniz Dias ${ }^{1,3, *}$, Aluana Gonçalves Abreu ${ }^{2}$, Fábio de Oliveira Morais e Silva ${ }^{2}$, \\ Vera Nisaka Solferini ${ }^{2}$
}

${ }^{1}$ Pós-Graduação em Ecologia, and ${ }^{2}$ Departamento de Genética e Evolução, Instituto de Biologia, Universidade Estadual de Campinas, CP 6109, CEP 13083-970 Campinas SP, Brazil

${ }^{3}$ Present address: School of Integrative Biology, University of Queensland, 4072 Queensland, Australia

\begin{abstract}
Ascidians, like most encrusting organisms, present polymorphisms in shape and color that are frequently attributed to the environmental conditions in which the adults live. In southeastern Brazil, the ascidian Trididemnum orbiculatum presents 2 morphotypes that occur along different parts of the rocky shoreline. Between the intertidal and subtidal zones, the morphotypes differ in numerous characters, such as the pigmentation of zooids, growth pattern of the colony and abundance of spicules. We assessed the differentiation between the morphotypes using morphological and allozyme data. Characters traditionally used in ascidian taxonomy did not separate the morphotypes into distinct species, but the intertidal morphotype presented consistently smaller zooids, larvae and colony thickness, possibly caused by the harsh conditions of this zone. Although most of this divergence could be caused by phenotypic plasticity, clear genetic structure was observed between morphotypes. We propose that the morphotype from the subtidal zone constitutes a different species from that in the intertidal zone. In addition, morphological and genetic data suggest that colonies from the intertidal zone constitute more than one genetic entity.
\end{abstract}

KEY WORDS: Ascidian $\cdot$ Allozyme $\cdot$ Intertidal zone $\cdot$ Subtidal zone

\section{INTRODUCTION}

The significance and maintenance of polymorphism (e.g. shape, color, size) is a well-studied theme both in ecology and evolutionary biology (Hedrick 1976, Merilaita 2001, Tarjuelo et al. 2004). Many species of marine invertebrates display color polymorphisms, in which the frequencies of different morphotypes vary among habitats, sites, and times (Wicksten 1989). The expression of color variation may be environmentally, ontogenetically, or genetically controlled (e.g. Oetinger \& Nichol 1982, Bedini 2002). In the first 2 cases, habitat-specific and geographic variation in the distribution of morphs may reflect variation in the distribu- tion of environmental factors such as diet composition, predation intensity, or pathogens. In other species, coloration may be genetically based, and spatially variable selection appears to play a role in the distribution of color variants (e.g. Sabbadin \& Graziani 1967, Ekendahl \& Johannesson 1997, Hargeby et al. 2004).

Colonial ascidians, like other benthic invertebrates, show great morphological variability in shape, size, and color due to genetic characteristics and local environmental conditions. This variability complicates species identification by traditional methods, and, in general, chromatic varieties have not received any valid taxonomic status (Monniot et al. 1991). In Botryllys schlosseri, polychromatism is regulated by a few 
Mendelian loci and is clearly an intraspecific feature (Yund \& O'Neil 2000). López-Legentil \& Turon (2005) concluded that color variation in Cystodytes dellechiajei correlates with genetic differences, but may not be enough to differentiate species. On the other hand, Dalby (1997) found genetic differentiation between color varieties of Pyura stolonifera. In addition, the 2 chromatic varieties of Pseudodistoma crucigaster Gaill, 1972 correspond to 2 sibling species, according to molecular data (Tarjuelo et al. 2004).

On the southeastern coast of Brazil, the ascidian genus Trididemnum Della Valle, 1881 presents 1 single valid species: Trididemnum orbiculatum (Van Name, 1902). This species, which is found on rocks or in crevices in the subtidal and intertidal zones, is widely distributed in tropical seas, such as those of Bermuda, Curaçao, Guadalupe, and the region of São Paulo State, Brazil (Rodrigues \& Rocha 1993). T. orbiculatum presents 2 morphotypes. One is common in the intertidal zone, presenting green or yellowish colonies with sparse spicules and 2-directional growth. Its zooids possess black pigment in the anterior portion of the endostyle and in the tips of the lobes of the branchial siphon. The second morphotype is more abundant in the subtidal zone, and forms white, gray, or yellowish colonies with innumerous folds in the tunic and large spiked spicules widely found in the upper tunic layer. Its zooids show a completely pigmented thorax (Rodrigues et al. 1998, Lotufo 2002). Colonies of the morphotype common in the intertidal zone are similar to those described by Van Name (1945) as Trididemnum thetidis. This last species was described based on immature individuals in which no larvae or gonads were observed, making its taxonomy doubtful. However, Monniot (1983), in a discussion regarding Guadalupe's didemnids, suggested that $T$. orbiculatum is very similar to $T$. thetidis and proposed its synonymy.

Given the variable morphology and lack of distinctive characters, molecular characterization could be a valuable aid to the identification of species in polymorphic groups (e.g. Tarjuelo et al. 2004). The allozyme technique, which is often used in systematic studies, is effective in revealing population structure and in determining species limits. Using this tool, Aron \& Solé-Cava (1991) determined that 2 morphotypes of the ascidian Botryllus niger were, in fact, 2 different species. Similar studies have been developed for marine sponges by Solé-Cava \& Thorpe (1986), for mussels by McDonald et al. (1991), and for ascidians by Dalby (1997).

The goal of the present study was to investigate the degree of morphological and genetic differentiation between the 2 morphotypes of Trididemnum orbiculatum and to clarify their taxonomic status.

\section{MATERIALS AND METHODS}

Sampling and study organism. Colonies of Trididemnum orbiculatum were sampled from 9 to 12 July 2005, at 4 beaches in São Sebastião city, on the north coast of São Paulo State, southeastern Brazil: Praia do Segredo $\left(23^{\circ} 49^{\prime} 42^{\prime \prime} \mathrm{S}, 45^{\circ} 25^{\prime} 22^{\prime \prime} \mathrm{W}\right)$, Praia Grande (23 $49^{\prime} 23^{\prime \prime} \mathrm{S}$, $\left.45^{\circ} 25^{\prime} 01^{\prime \prime} \mathrm{W}\right)$, Praia Preta $\left(23^{\circ} 49^{\prime} 23^{\prime \prime} \mathrm{S}, 45^{\circ} 25^{\prime} 01^{\prime \prime} \mathrm{W}\right)$, and Praia de Barequeçaba ( $\left.23^{\circ} 49^{\prime} 46^{\prime \prime} \mathrm{S}, 45^{\circ} 26^{\prime} 28^{\prime \prime} \mathrm{W}\right)$. A small area of each sampled colony was removed and stored in liquid nitrogen for the allozyme analyses, and another piece was stored in $70 \%$ alcohol for the morphological analyses, both after being anesthetized with crystals of menthol.

In the intertidal zone of Praia Preta, some colonies presented an intermediate morphology between the 2 morphotypes described in the literature and were classified as a third morphotype, the yellow one. Therefore, we divided the colonies of Trididemnum orbiculatum into 3 categories: (1) green morphotype: colonies common in the intertidal zone with sparse spicules and black pigment in the anterior portion of the endostyle and in the tips of the lobes of the branchial siphon, described by Van Name (1945) as T. thetidis; (2) white morphotype: colonies common in the subtidal zone with densely packed spicules, a completely pigmented thorax and a 'melted candle' appearance; (3) yellow morphotype: yellow colonies with small folds, spicules with intermediate abundance, and zooids pigmented as described for the green morphotype, found in the intertidal zone of a single location, Praia Preta.

A total of 25 colonies of the white morphotype were sampled from each of the 4 beaches. For the yellow and green morphotypes, we collected samples of all colonies that were available at each beach. The green morphotype was found in Praia Preta and Praia do Segredo, and 12 colonies were sampled from each beach; 16 colonies of the yellow morphotype were sampled in Praia Preta. Voucher specimens have been deposited in the Museu de Zoologia, Universidade de São Paulo, São Paulo, Brazil (MZUSP): white (MZUSP Nos. 17350, 17351, 17352, 17355); green (MZUSP Nos. 17353, 17354, 17356); yellow (MZUSP Nos. 17357 17358).

Morphological analyses. After fixation, colonies were cut into thin slices and decalcified with a solution of EDTA $10 \%$ for visualization and measurement of the zooids. This method seems to be more precise than the measurement of the removed thorax and abdomen, because it considers the real length of the esophageal-rectal peduncle. Spicules were obtained by dissociation in sodium hypochlorite and then mounted on glass slides.

Totals of 10 spicules and 10 zooids were randomly selected and analyzed for each colony; 19 colonies 
from Praia do Segredo (10 white and 9 green) were analyzed, as well as 10 colonies from Praia de Barequeçaba (white morphotype), 27 colonies from Praia Preta (10 white, 9 green, and 8 yellow), and 10 colonies from Praia Grande (white morphotype).

We measured each colony's thickness and described its coloration and growth pattern. Thickness was measured under a stereomicroscope in 3 different portions of the colony slices. Afterwards, we measured 10 spicules colony $^{-1}$ and described their shape, distribution, and abundance. In each zooid (10 zooids colony $\left.{ }^{-1}\right)$, we described the following: pigmentation; position of the lateral organ in the thorax; length of thorax, abdomen, and muscular process; and numbers of lobes in the branchial siphon, stigmata per half-row, and intestinal constrictions. In mature zooids, we counted the number of testis lobes, oocytes in the ovary, and spermiduct coils. When larvae were present, we counted the numbers of adhesive papillae and pairs of ampullae, and measured the length of the tail and trunk (10 larvae colony ${ }^{-1}$ ).

To avoid problems associated with character correlation, significant differences among morphotypes were first determined using multivariate analyses. For each colony, the average sizes of thorax, abdomen, spicule, and colony thickness were log-transformed to fit multivariate normality and homocedasticity and used in a 1-way MANOVA, followed by a pairwise Hotteling's $T^{2}$ test. These tests were used to determine if significant differences exist among morphotypes. As the MANOVA was significant, corresponding 1-way ANOVAs were subsequently performed for each character alone, followed by Bonferroni post hoc tests between the 7 OTUs (operational taxonomic units): white morphotype from Praia de Barequeçaba, Praia Grande, Praia do Segredo, and Praia Preta; yellow morphotype from Praia Preta; and green morphotype from Praia Preta and Praia do Segredo.

A stepwise discriminant analysis (SDA) was performed to investigate the integrity of pre-defined morphotypes ( $F$ to enter $3.84, F$ to remove 2.71 ). This statistical analysis builds a predictive model of group membership based on the observed characteristics of each sample (Hanelt \& Janovy 2002). Each colony was allocated to the morphotype with the nearest centroid, and the proportion of colonies correctly assigned according to pre-defined classification was calculated. The analysis also maximizes differences between morphotypes and minimizes stepwise analysis, determining which of the characters are the most important in discriminating between morphotypes (Hanelt \& Janovy 2002). The canonical discriminant functions were graphically represented in a scatterplot.

Discrete or categorical variables were not used in MANOVA or SDA, because they render the multivari- ate analyses inefficient (James \& McCulloch 1990). Larval size was not used, because not all colonies sampled were incubating larvae and the analyses do not accept missing data. Larval size was compared between morphotypes by an ANOVA that excluded colonies without larvae. Statistical tests were performed in SYSTAT 12 and SPSS 14.0.

Allozyme analysis. Protein extracts were prepared by homogenizing small pieces of frozen tissue in $30 \mu \mathrm{l}$ of $1.22 \mathrm{M}$ Tris-citrate buffer, $\mathrm{pH} 8.0$, containing $0.05 \%$ $(\mathrm{v} / \mathrm{v}) \beta$-mercaptoethanol. The extracts were then absorbed in Whatman No. 3 paper wicks $(1.0 \times 0.3 \mathrm{~cm})$, which were loaded onto horizontal $8.5 \%$ starch gels. Three buffer systems were used: (1) electrode: $10 \mathrm{mM}$ lithium hydroxide, $90 \mathrm{mM}$ boric acid, $3 \mathrm{mM}$ EDTA, adjusted $\mathrm{pH}$ 8.0; gel: electrode solution diluted 1:10; (2) electrode: $0.04 \mathrm{M}$ citric acid and N(3-aminopropil) morpholine, pH 7.5 adjusted; gel: electrode solution diluted 1:20; (3) electrode: $78 \mathrm{mM}$ citric acid, $0.34 \mathrm{M}$ Tris, pH 8.6 adjusted; gel: $2.5 \mathrm{mM}$ citric acid, $38 \mathrm{mM}$ Tris, pH 8.6 adjusted (Andrade et al. 2003). System 1 was used to characterize aldehyde oxidase (AO; EC 1.2.3.1), isocitrate dehydrogenase (IDH; EC 1.1.1.42), phosphoglucomutase (PGM; EC 2.7.5.1), and catalase (CAT; EC 1.11.1.6); System 2 was used to characterize aspartate aminotransferase (AAT; EC 2.6.1.1) and malate dehydrogenase ( $\mathrm{MDH}_{i} \mathrm{EC}$ 1.1.1.37); and System 3 was used to characterize adenylate kinase $\left(\mathrm{AK}_{\mathrm{i}}\right.$ EC 2.7.4.3) and hexokinase (HK; EC 2.7.1.1).

Analyses were performed by grouping all individuals from each locality (4 OTUs) and also according to morphotype and locality (7 OTUs). Measures of genetic diversity (percentages of polymorphic loci, mean numbers of alleles per locus, observed and expected heterozygosities) were estimated using GENETIX 4.05.2 (Belkhir et al. 2004). F-statistics were calculated by the method of Weir \& Cockerham (1984) (estimators $\theta$ and $f$ ), and their significances (5\% level) were tested by bootstrapping in GENETIX 4.05.2. Tests for deviations from Hardy-Weinberg equilibrium (by exact tests) and for linkage disequilibrium were calculated using GENEPOP 3.3 (Raymond \& Rousset 1995). Sequential Bonferroni tests were used to correct for multiple comparisons.

Pairwise genetic distances between pairs of samples were computed using Nei's standard genetic distance (Nei 1972), obtained from GENETIX 4.05.2. Distance trees were reconstructed using the neighbor-joining method in the MEGA program (Kumar et al. 2004).

The assignment of individuals to populations and the proportions in mixtures estimated on the basis of multilocus genotype data were implemented in the STRUCTURE program (Falush et al. 2007). The model randomly assigns individuals to source clusters (or jointly to 2 or more clusters, in cases of admixture) on 
the basis of their genotypes, while simultaneously estimating allelic frequencies; 20 independent runs were carried out for each value of a number $K$ ( $K$ from 1 to 6 ) of clusters. For each run, 2000000 iterations were carried out after a burn-in period of 200000 iterations. The true value of $K$ was chosen on the basis of the second-order rate of change of the log-likelihood function with respect to $K\left(\Delta K_{\text {; }}\right.$ Evanno et al. 2005). Analyses were initially performed without prior assumptions concerning the population (phenotype or geographical location). Simulations were then carried out for $K=2$ ( 2 clusters).

\section{RESULTS}

\section{Morphological analysis}

The morphological traits traditionally used in the taxonomy of the Family Didemnidae did not differ among the 3 morphotypes (see Appendix 1). All colonies presented spicules of conical rays restricted to the upper areas of the colonies, but not in the most superficial layer. The zooid presented 7 to 12 stigmata per half-row in the first row of the pharynx, a short retractor muscle, and the lateral organ located between the second and third rows of stigmata. Except for a few cases, most zooids presented only 1 oocyte in the ovary, and the testis was always undivided and covered by 6 spermiduct coils. The larvae presented 4 pairs of ampullae, 3 adhesive papillae, and had a tail winding up half of the larval trunk. The qualitative morphological differences between the 3 morphotypes were restricted to the growth pattern of the colony (3-dimensional in the white morphotype and 2dimensional in the yellow and green morphotypes), their pigmentation (used to categorize the colonies), and the concentration of spicules (abundant in the white morphotype, intermediate in the yellow morphotype, and scarce or absent in the green morphotype).

MANOVA revealed significant differences between all morphotypes (Wilks' $\Lambda=0.001, F_{(12,161)}=182.19$, p < 0.001 ), and all characters were found to have significant differences when considered individually (Table 1). All morphological traits were smaller in the green morphotype than in the white morphotype. The yellow morphotype presented similar sizes of abdomen, larvae, and colony thickness to the green morphotype; a similar thorax size to the white morphotype; and a similar spicule size to both other morphotypes. No differences were observed between populations of the green morphotype, but thorax and abdomen sizes differed among populations of the white morphotype (Fig. 1).

Assignment of colonies to the morphotypes performed by discriminant analysis correctly classified 63 of 67
Table 1. Trididemnum orbiculatum. One-way ANOVA of colony thickness and the sizes of the thorax, abdomen, spicule, and larval trunk between different populations of the white, green, and yellow morphotypes; $\mathrm{p}<0.001$ for each source

\begin{tabular}{|lcccc|}
\hline Source & SS & df & MS & $F$ \\
\hline Colony thickness & 21.484 & 6 & 3.581 & 39.807 \\
Error & 5.397 & 60 & 0.090 & \\
Thorax & 0.386 & 6 & 0.064 & 37.626 \\
Error & 0.103 & 60 & 0.002 & \\
Abdomen & 0.155 & 6 & 0.026 & 31.072 \\
Error & 0.05 & 60 & 0.001 & \\
Spicule & 0.440 & 6 & 0.073 & 11.924 \\
Error & 0.369 & 60 & 0.006 & \\
Larvae & 0.020 & 6 & 0.003 & 15.101 \\
Error & 0.007 & 31 & 0.000 & \\
\hline
\end{tabular}

(94\%) colonies, showing high-resolution discrimination between morphotypes. The first canonical discriminant function explained $94.9 \%$ of the total variance and presented colony thickness as the character with the largest standardized coefficient. The second canonical discriminant function accounted for $5.1 \%$ of the total variance and presented thorax size as the character with the largest standardized coefficient. The plot of the canonical functions shows a graphic separation between the 3 groups. The white morphotype was separated from the other 2 by Function 1 ; the yellow and green morphotypes were separated from each other by Function 2 (Fig. 2). Stepwise discriminant analysis considered colony thickness and thorax and abdomen sizes as valuable characters for discriminating between morphotypes, but not spicule size.

\section{Allozyme analysis}

Of the 8 assayed loci, Pgm was monomorphic for all morphotypes and Ao was monomorphic for the white morphotype. When grouped according to morphotype and sample location, the locus Aat separated the white morphotype (Aat4) from the others (Aat3). Three alleles were restricted to the green morphotype (Mdh6, Me6, and Me7), and 1 to YP and GS (Cat5), all at high frequencies. Private alleles (rare alleles found only in 1 sample) were Me6 and Ao2 in GP and Idh3, Cat3, $A k 2$, and $A k 5$ in WS (Table 2).

Genetic variability is described in Table 3. The mean gene diversity $\left(H_{\mathrm{e}}\right)$ was 0.183 , the mean number of alleles per locus $(A)$ was 1.81 , and the mean percentage of polymorphic loci was $44 \%$. Significant linkage disequilibrium was detected only in sample WS, and departures from the Hardy-Weinberg equilibrium (HWE, at $5 \%$ significance level, after a Bonferroni correction) were detected in loci $M e(\mathrm{WB}), M d h(\mathrm{WB})$, and 

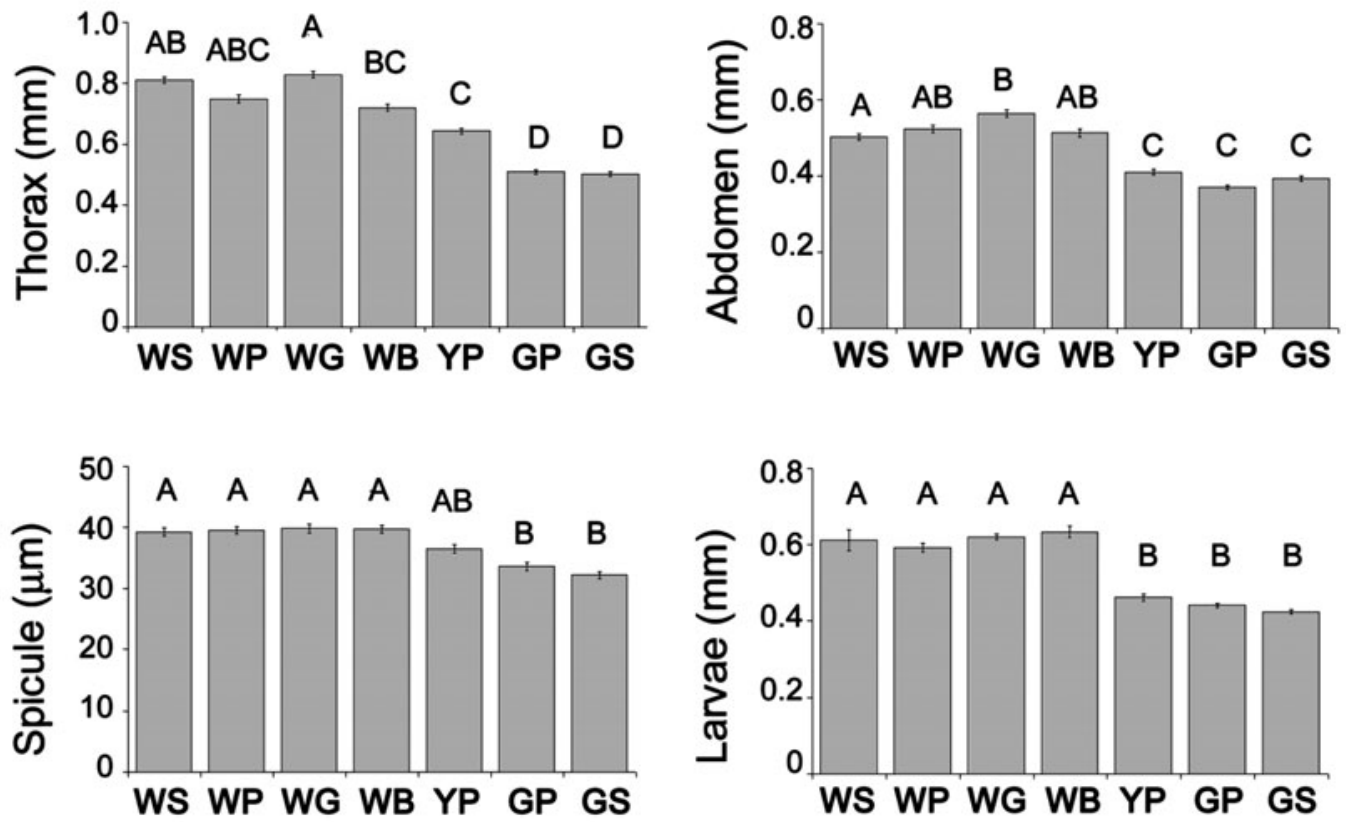

Fig. 1. Trididemnum orbiculatum. Thorax size, abdomen size, spicule size, larval length, and colony thickness (mean $\pm \mathrm{SE}$ ). WS: white Praia do Segredo; WP: white Praia Preta; WG: white Praia Grande; WB: white Praia de Barequeçaba; YP: yellow Praia Preta; G: green Praia Preta; GS: green Praia do Segredo. The letters above bars represent the similarities for the Bonferroni post hoc test $(\mathrm{p}<0.05)$

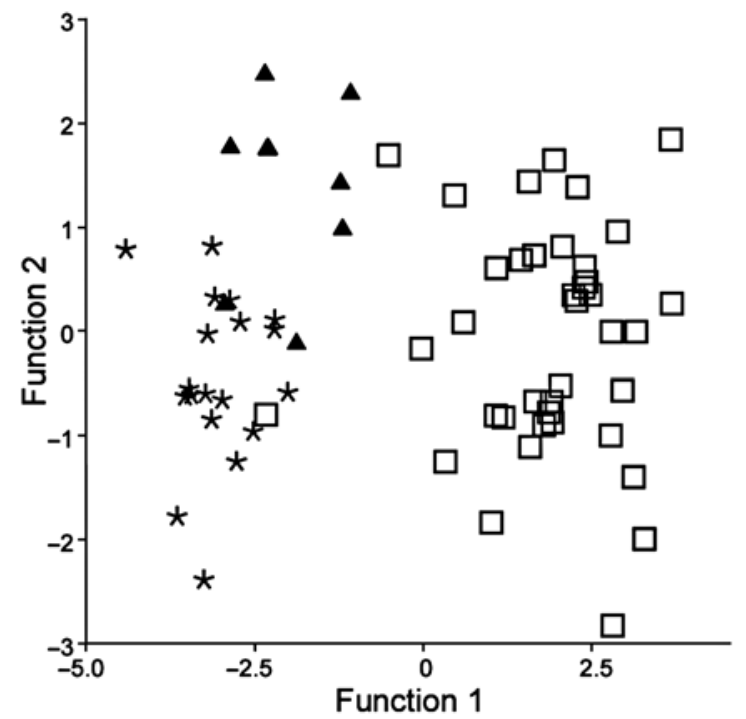

Fig. 2. Trididemnum orbiculatum. Two-dimensional plot of morphological traits analyzed by canonical discriminant analysis. Morphotypes: $(\square)$ white; $(\mathbf{\Lambda})$ yellow; $(*)$ green

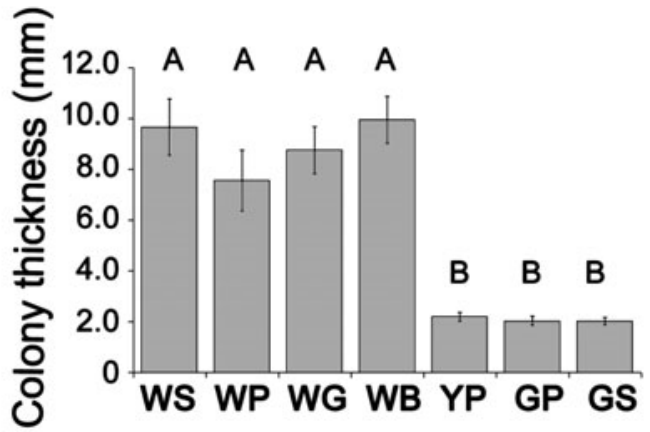

$H k$ (WB, WS, GS). All significant deviations had high and positive $f$-values, indicating deficiencies of heterozygotes. Sample WS was the most variable in all morphotypes. The fixation index $(\theta)$ was 0.12 (range: 0.08 to 0.19 ) when separated only by location, 0.58 (range: 0.41 to 0.77 ) when separated only by morphotype, and 0.486 (range: 0.37 to 0.69 ) when separated by location and morphotype.

Genetic relationships between samples are presented in the UPGMA phenogram (Fig. 3). All samples of the white morphotype grouped in the same cluster; the yellow morphotype from Praia Preta and the green morphotype from Praia do Segredo were in another branch, and the green morphotype from Praia Preta was alone in the outer branch. Genetic distances ranged from 0.008 to 0.053 between samples of the white morphotype, but ranged from 0.409 to 1 between samples of the white morphotype and the other 2 morphotypes.

Cluster analysis revealed that the most likely genetic structure for the whole dataset consisted of 2 clusters $(\Delta K=2)$. One cluster grouped together $98 \%$ of all 
Table 2. Trididemnum orbiculatum. Allele frequencies for the 7 polymorphic allozyme loci from morphotypes. WS: white Praia do Segredo; WP: white Praia Preta; WG: white Praia Grande; WB: white Praia de Barequeçaba; YP: yellow Praia Preta; GP: green Praia Preta; GS: green Praia do Segredo

\begin{tabular}{|c|c|c|c|c|c|c|c|c|}
\hline Locus & Allele & WB & WG & WP & WS & YP & GS & GP \\
\hline \multicolumn{9}{|l|}{ Ao } \\
\hline \multirow[t]{3}{*}{$(\mathrm{N})$} & & 25 & 28 & 21 & 25 & 16 & 5 & 6 \\
\hline & 2 & - & - & - & - & - & - & 1.00 \\
\hline & 4 & 1.00 & 1.00 & 1.00 & 1.00 & 1.00 & 1.00 & - \\
\hline \multicolumn{9}{|l|}{$I d h$} \\
\hline \multirow[t]{4}{*}{$(\mathrm{N})$} & & 25 & 16 & 16 & 16 & 11 & 6 & 6 \\
\hline & 3 & - & - & - & 0.06 & - & - & - \\
\hline & 4 & 1.00 & 1.00 & 1.00 & 0.78 & 0.91 & 0.33 & 1.00 \\
\hline & 5 & - & - & - & 0.16 & 0.09 & 0.67 & - \\
\hline \multicolumn{9}{|l|}{ Cat } \\
\hline \multirow[t]{5}{*}{$(\mathrm{N})$} & & 24 & 23 & 20 & 24 & 15 & 6 & 4 \\
\hline & 3 & - & - & - & 0.04 & - & - & - \\
\hline & 4 & 0.98 & 0.98 & 1.00 & 0.88 & - & 0.08 & 0.75 \\
\hline & 5 & - & - & - & - & 1.00 & 0.83 & - \\
\hline & 6 & 0.02 & 0.02 & - & 0.08 & - & 0.08 & 0.25 \\
\hline \multicolumn{9}{|l|}{ Aat } \\
\hline \multirow[t]{4}{*}{$(\mathrm{N})$} & & 27 & 22 & 22 & 21 & 16 & 4 & 4 \\
\hline & 3 & - & 0.02 & 0.05 & 0.02 & 0.97 & 0.88 & 1.00 \\
\hline & 4 & 1.00 & 0.95 & 0.95 & 0.90 & 0.03 & - & - \\
\hline & 5 & - & 0.02 & - & 0.07 & - & 0.13 & - \\
\hline \multicolumn{9}{|l|}{$M e$} \\
\hline \multirow[t]{6}{*}{$(\mathrm{N})$} & & 17 & 14 & 15 & 28 & 13 & 3 & 7 \\
\hline & 3 & 0.06 & - & 0.07 & - & - & 0.67 & - \\
\hline & 4 & 0.62 & 0.32 & 0.47 & 0.51 & 0.69 & - & - \\
\hline & 5 & 0.32 & 0.68 & 0.47 & 0.48 & 0.31 & - & - \\
\hline & 6 & - & - & - & - & - & - & 0.86 \\
\hline & 7 & - & - & - & - & - & 0.33 & 0.14 \\
\hline \multicolumn{9}{|l|}{$M d h$} \\
\hline \multirow[t]{4}{*}{$(\mathrm{N})$} & & 25 & 13 & 14 & 28 & 16 & 10 & 11 \\
\hline & 4 & 0.68 & 0.35 & 0.50 & 0.52 & 0.97 & 0.35 & - \\
\hline & 5 & 0.32 & 0.65 & 0.50 & 0.48 & 0.03 & - & - \\
\hline & 6 & - & - & - & - & - & 0.65 & 1.00 \\
\hline \\
\hline \multirow[t]{5}{*}{$(\mathrm{N})$} & & 17 & 4 & 18 & 28 & 16 & 5 & 7 \\
\hline & 2 & - & - & - & 0.02 & - & - & - \\
\hline & 3 & - & - & - & 0.02 & - & - & 1.00 \\
\hline & 4 & 1.00 & 1.00 & 1.00 & 0.95 & 1.00 & 1.00 & - \\
\hline & 5 & - & - & - & 0.01 & - & - & - \\
\hline \multicolumn{9}{|l|}{$H k$} \\
\hline \multirow[t]{7}{*}{$(\mathrm{N})$} & & 25 & 11 & 15 & 29 & 16 & 7 & 11 \\
\hline & 4 & 0.24 & 0.68 & 0.73 & 0.67 & 0.06 & - & - \\
\hline & 5 & 0.42 & 0.32 & 0.10 & 0.12 & - & - & - \\
\hline & 6 & 0.34 & - & 0.17 & 0.09 & - & 0.29 & 0.55 \\
\hline & 7 & - & - & - & 0.09 & - & 0.29 & 0.41 \\
\hline & 8 & - & - & - & 0.02 & 0.94 & 0.42 & - \\
\hline & 9 & - & - & - & 0.02 & - & - & 0.05 \\
\hline
\end{tabular}

white morphs (W), and the other grouped 96 and $93 \%$ of the yellow and green morphs $(\mathrm{Y}+\mathrm{G})$, respectively. When we used phenotypic information as prior clustering information $(K=2, \mathrm{~W}$ and $\mathrm{Y}+\mathrm{G}), 93.5 \%(101 / 108)$ of the white individuals and $90 \%(36 / 40)$ of the yellow and green specimens were assigned to the appropriate cluster with a probability $\geq 0.90$. The remaining 7 white individuals (5 WS, $1 \mathrm{WG}$, and $1 \mathrm{WP}$ ) and $4 \mathrm{Y}+\mathrm{G}$ individuals (1 YP, 1 GS, and 2 GP) had an assignment probability $<0.90$, indicative of mixed ancestry (Fig. 4).
Table 3. Trididemnum orbiculatum. Genetic variability by sampling location and morphotype. $N$ : number of individuals analyzed; $H_{\mathrm{e}}$ : gene diversity; $H_{\mathrm{o}}$ : mean observed heterozygosity; $P$ : percent of polymorphic loci; $A$ : mean number of alleles per locus; $f$ : inbreeding coefficient; NS: non-significant values at $\mathrm{p}=0.05$

\begin{tabular}{|lcccccl|}
\hline & $N$ & $H_{\mathrm{e}}$ & $H_{\mathrm{o}}$ & $P$ & $A$ & $f$ \\
\hline Location & & & & & & \\
Barequeçaba & 27 & 0.18 & 0.04 & 0.33 & 1.67 & 0.77 \\
Grande & 28 & 0.16 & 0.16 & 0.33 & 1.67 & $0.05(\mathrm{NS})$ \\
Preta & 51 & 0.40 & 0.08 & 0.78 & 2.89 & 0.80 \\
Segredo & 42 & 0.36 & 0.15 & 0.67 & 3.22 & 0.60 \\
Mean & 37 & 0.28 & 0.11 & 0.53 & 2.36 & 0.67 \\
Morphotype & & & & & & \\
White & 108 & 0.22 & 0.12 & 0.33 & 2.89 & 0.44 \\
Yellow & 16 & 0.09 & 0.08 & 0.33 & 1.56 & $0.15(\mathrm{NS})$ \\
Green & 24 & 0.40 & 0.04 & 0.89 & 2.33 & 0.91 \\
Mean & 49.3 & 0.24 & 0.08 & 0.52 & 2.26 & 0.53 \\
\hline
\end{tabular}

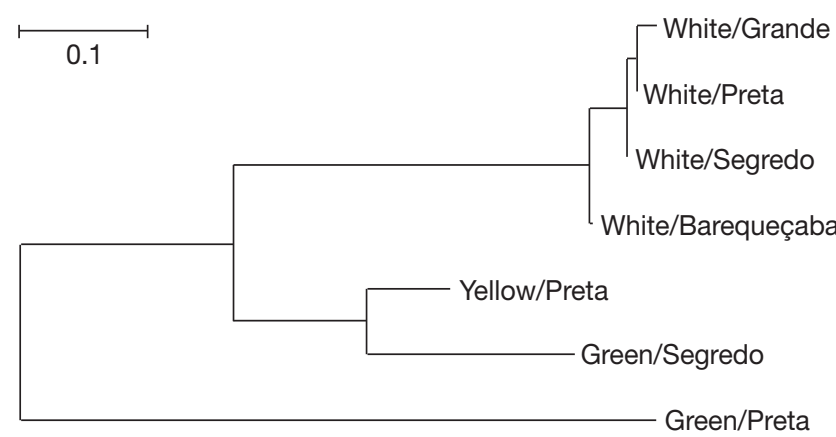

Fig. 3. Trididemnum orbiculatum. Neighbor-joining cluster analysis based on Nei's (1972) genetic distance estimated between the samples of $T$. orbiculatum

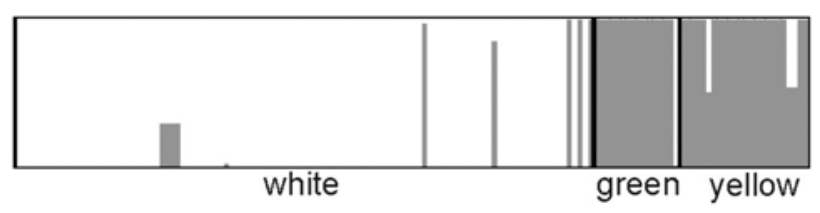

Fig. 4. Trididemnum orbiculatum. Best clustering result $(K=$ 2) by STRUCTURE, using allozyme data. Each individual is represented as a vertical line partitioned into colored segments, the length of which is proportional to the individual's estimated $K$ cluster membership coefficients

\section{DISCUSSION}

Analyses of the characters traditionally used in the taxonomy of ascidians support the synonymy proposed by Monniot (1983) for the species Trididemnum orbiculatum and $T$. thetidis, represented in the present study by the white and green morphotypes, respectively. 
Morphotypes were similar to each other in most morphological characters, even in those that were not described by Van Name (1945), such as the number of coils around the testis, the number of testis lobes, and the numbers of papillae and pairs of ampullae in the larvae. Nevertheless, they differed in colony growth pattern and thickness, colony and zooid pigmentation, and in the sizes of zooids and larvae. These differences are frequently attributed to the environmental conditions in the areas in which colonies live, and usually delimit morphotypes or ecotypes (López-Legentil \& Turon 2005), but not different species.

Our multivariate approach separated the morphotypes into 3 distinct groups, with discriminant analysis misclassifying only 4 of 67 colonies. The white morphotype presented thicker colonies than the yellow and green morphotypes, while these last 2 differed from each other in the size of the thorax, which was larger in the yellow morphotype. Colony thickness is rarely used in ascidian taxonomy because very young colonies can bias the analysis, but for Trididemnum orbiculatum it seems to be a reliable character for discriminating between the white morphotype and the other 2 . In contrast, the use of thorax size to separate the green and yellow morphotypes should be done with caution, since significant differences in thorax size between populations of the white morphotype suggest that it may be of limited reliability in discriminating between morphotypes.

The miniaturization observed in colonies of yellow and green morphotypes living in the intertidal could be attributed to the harsh conditions typical of this zone. Animals inhabiting this area are frequently smaller than related species that inhabit the subtidal (Kemppainen et al. 2005), because the risk of dislodgment by wave action restricts the growth of sessile organisms to a 2-directional pattern. In addition, these animals are frequently found in protected places, such as crevices, caves, or on the undersurfaces of rocks, which also restricts their 3-dimensional growth. In this way, the distinction between intertidal and subtidal morphotypes of Trididemnum orbiculatum could be the result of phenotypic plasticity in response to differences in the abiotic conditions between the areas that they occupy, as proposed by Monniot (1983). However, there was clear genetic structure between the subtidal (white) morphotype and those (yellow and green) from the intertidal; this was even stronger than between different populations of the same morphotype, suggesting that morphotypes are actually distinct species. This is evident when genetic structure is compared between the 3 morphotypes from a single beach $(\theta$ Preta $=$ $0.76)$ and all white morphotype samples $(\theta=0.07)$.

Many loci separate the white morphotype from the green one or the yellow one, but only a single locus,
Aat, separates the white morphotype from the other 2 simultaneously: allele Aat4 is more frequent (0.91 to 1.00) in subtidal morphotypes and allele Aat 3 is more frequent $(0.87$ to 1.00$)$ in the other morphotypes. Significant allele frequency differences at this locus have already been observed in the gastropod Littorina saxatilis between close populations from intertidal and subtidal zones (Johannesson \& Johannesson 1989). In mollusks, Aat is associated with anaerobic respiration, and different alleles provide different intensities of enzyme activity. Alleles that are more frequent in the intertidal zone may be selected because they provide greater resistance to water loss, which is crucial in organisms that stay exposed to air for longer periods (Johannesson \& Tatarenkov 1997). For ascidians, there is no evidence of different alleles providing different levels of resistance to water loss, and this hypothesis was not tested in the present study. In any case, this difference at Aat, as well as at other loci, is evidence that the Trididemnum orbiculatum morphs represent sympatric populations that are reproductively isolated.

Divergent selection pressures can play significant roles in promoting rapid adaptive radiation and local speciation (Schluter 2001). They may produce adaptations that simultaneously allow species to coexist and reduce gene flow. Palumbi (1994) proposed 4 prezygotic mechanisms of reproductive isolation for marine species: mate preference, habitat specialization, spawning asynchrony, and unsuccessful fertilization. Asynchronic spawning has been cited as causing genetic divergence in periwinkles (Andrade \& Solferini 2007) and ascidians (Pérez-Portela et al. 2007), and could be responsible for part of the genetic pattern observed between intertidal and subtidal morphotypes. Most ascidians spawn when stimulated by light, so gametes are released at dawn (C. Lambert 2005). Usually, an intensification of ascidian reproduction occurs during spring and summer (G. Lambert 2005), during which time the lowest tides occur in the early morning in our sampling area. Thus, intertidal morphotypes are exposed to air soon after releasing gametes, which reduces the opportunity for fertilization between these and subtidal morphotypes. Moreover, larvae of the subtidal morphotype may have few chances of colonizing higher portions of the shore. Habitat specialization driven by direct selection (observed in Tatarenkov \& Johannesson 1994, Dhuyvetter et al. 2007) can also contribute to reproductive isolation between ecotypes, since it seems powerful enough to generate partial reproductive isolation without reinforcement (Kirkpatrick \& Ravigné 2002). In addition, there could be a post-zygotic barrier via ecological inviability, i.e. hybrids develop normally but suffer lower viability because they cannot find an appropriate ecological niche. 
The analysis of allozyme variation demonstrated that the white morphotype should be considered a species that differs from the yellow and green morphotypes found in the intertidal. Further experiments with Trididemnum orbiculatum demonstrated that spicules at densities found in the subtidal morphotype are important in inhibiting fish predation (G. M. Dias et al. unpubl. data). Predation by fishes is expected to be stronger in the subtidal zone (Rooper et al. 1999), and could be a selective pressure on spicule density: the more spicules, the less predation. If predation removes individuals with small abundances of spicules, larvae from intertidal colonies that settle in the subtidal zone will be removed by predators, which would enhance morphological divergence between morphotypes. Since differences between morphotypes were in characters different from the ones conventionally used in taxonomy, we propose classification of the 2 morphotypes (white and green + yellow) as sibling species. Occasionally, marine species can acquire comparatively high levels of genetic differentiation without showing morphological differences that taxonomists would regard as adequate to indicate speciation (Morrow et al. 1992).

In the intertidal, on the other hand, we cannot define how many species there are. If green and yellow morphotypes were conspecific, sympatric samples should demonstrate no significant differences in allele frequencies, because conspecific individuals interbreed freely in accordance with the biological definition of species. However, when green and yellow morphotypes from Praia Preta were analyzed as a single population, there was linkage disequilibrium at several pairs of loci, which does not remain when they were analyzed as different populations. This shows that green and yellow morphotypes cannot be considered the same genetic entity and apparently constitute 2 incipient species. In a similar way, the 2 samples of the green morphotype are too different to represent a single unity. Genetic identity (I) between green samples is only 0.22 , a value below the critical level for $I$-values (0.35) distinguishing between species and genera (Thorpe 1982). The taxonomic implications of $I$-values are clear. If allopatric populations of dubious status have genetic identities below about 0.85 , it is improbable that they should be considered conspecific. These differences may reflect restricted gene flow as well as sampling bias and/or random effects such as founding events and genetic drift. For the time being, the taxonomic status of the intertidal varieties cannot be definitely assessed because our sample size is limited.

Our data describe a genetic division between yellow and green morphotypes from the intertidal zone and the white morphotype from the subtidal zone without an evident physical barrier. We propose that the species Trididemnum orbiculatum refers only to colonies such as those described in this manuscript as the white morphotype. Yellow and green morphotypes from the intertidal zone, on the other hand, present both morphological and genetic differences, but a larger sample is needed to clarify their taxonomic status and validation of the species designation $T$. thetidis.

Acknowledgements. The authors thank the Centro de Biologia Marinha da USP (CEBIMar-USP) for field support, G. Lambert, X. Turon, K. Monro, and 4 anonymous reviewers for valuable comments that greatly improved the manuscript. This study was supported by the Fundação de Amparo à Pesquisa do Estado de São Paulo through an undergraduate studentship to F.O.M.S. (Process 04/07440-7) and within the framework of the BIOTA/FAPESP program (Process 01/01994-2).

\section{LITERATURE CITED}

Andrade SCS, Solferini VN (2007) Fine-scale genetic structure overrides macro-scale structure in a marine snail: nonrandom recruitment, demographic events or selection? Biol J Linn Soc 91:23-36

Andrade SCS, Magalhães CA, Solferini VN (2003) Patterns of genetic variability in Brazilian littorinids (Mollusca): a macrogeographic approach. J Zool Syst Evol Res 41: 249-255

Aron S, Solé-Cava A (1991) Genetic evaluation of the taxonomic status of two varieties of the cosmopolitan ascidian Botryllus niger (Ascidiacea: Botryllidae). Biochem Syst Ecol 19:271-276

Bedini R (2002) Colour change and mimicry from juvenile to adult: Xantho poressa (Olivi, 1792) (Brachyura, Xanthidae) and Carcinus maenas (Linnaeus, 1758) (Brachyura, Portunidae). Crustaceana 75:703-710

Belkhir K, Borsa P, Chikhi L, Raufaste N, Bonhomme F (2004) GENETIX 4.05, logiciel sous Windows TM pour la génétique des populations. Laboratoire Génome, Populations, Interactions, CNRS UMR 5000, Université de Montpellier II, Montpellier

Dalby JE Jr (1997) Reproductive and electrophoretic evidence for genetic maintenance of dimorphism in the ascidian Pyura stolonifera near Melbourne, Australia. Ophelia 47: $227-243$

> Dhuyvetter H, Hendrickx F, Gaublomme E, Desender K (2007) Differentiation between two salt marsh beetle ecotypes: evidence for ongoing speciation. Evolution 61: 184-193

Ekendahl A, Johannesson K (1997) Shell colour variation in Littorina saxatilis Olivi (Prosobranchia: Littorinidae): a multi-factor approach. Biol J Linn Soc 62:401-419

- Evanno G, Regnaut S, Goudet J (2005) Detecting the number of clusters of individuals using the software structure: a simulation study. Mol Ecol 14:2611-2620

Falush D, Stephens M, Pritchard JK (2007) Inference of population structure using multilocus genotype data: dominant markers and null alleles. Mol Ecol Notes 7:574-578

> Hanelt B, Janovy J Jr (2002) Morphometric analysis of nonadult characters of common species of American gordiids (Nematomorpha: Gordioidea). J Parasitol 88:557-562

> Hargeby A, Johansson J, Ahnesjo J (2004) Habitat-specific pigmentation in a freshwater isopod: adaptive evolution over a small spatiotemporal scale. Evolution 58:81-94

Hedrick PW (1976) Genetic variation in a heterogeneous 
environment. II. Temporal heterogeneity and directional selection. Genetics 84:145-157

James FC, McCulloch CE (1990) Multivariate analysis in ecology and systematics: panacea or Pandora's box. Annu Rev Ecol Syst 21:129-166

Johannesson K, Johannesson B (1989) Differences in allele frequencies of Aat between high- and mid-rock shore populations of Littorina saxatilis (Olivi) suggest natural selection in this enzyme locus. Genet Res 54:7-11

Johannesson K, Tatarenkov A (1997) Allozyme variation in a snail (Littorina saxatilis) - deconfounding the effects of microhabitat and gene flow. Evolution 51:402-409

Kemppainen P, van Ness S, Ceder C, Johannesson K (2005) Refuge function of marine algae complicates selection in an intertidal snail. Oecologia 143:402-411

Kirkpatrick M, Ravigné V (2002) Speciation by natural and sexual selection: models and experiments. Am Nat 159 (Suppl):S22-S35

Kumar S, Tamura K, Nei M (2004) MEGA3: integrated software for molecular evolutionary genetics analysis and sequence alignment. Brief Bioinform 5:150-163

Lambert C (2005) Historical introduction overview and reproductive biology of the protochordates. Can J Zool 83:1-7

Lambert G (2005) Ecology and natural history of protochordates. Can J Zool 83:34-50

López-Legentil S, Turon X (2005) How do morphotypes and chemotypes relate to genotypes? The colonial ascidian Cystodytes (Polycitoridae). Zool Scr 34:3-14

Lotufo TMC (2002) Ascidiacea (Chordata: Tunicata) do litoral tropical brasileiro. PhD thesis, Universidade de São Paulo, São Paulo

> McDonald JH, Seed R, Koehn RK (1991) Allozymes and morphometric characters of three species of Mytilus in the northern and southern hemispheres. Mar Biol 111: 323-333

Merilaita S (2001) Habitat heterogeneity, predation and gene flow: colour polymorphism in the isopod Idotea baltica. Evol Ecol 15:103-116

Monniot F (1983) Ascidies littorals de Guadeloupe. I. Didemnidae. Bull Mus Natl Hist Nat Paris 4e Sér 5 A:5-49

Monniot C, Monniot F, Laboute P (1991) Coral reef ascidians of New Caledonia. Coléction faune tropicale XXX. ORSTOM Editions, Paris

Morrow CC, Thorpe JP, Picton BE (1992) Genetic divergence and cryptic speciation in two morphs of the common subtidal nudibranch Doto coronate (Opistobranchia: Dendronotacea: Dotoidae) from the northern Irish Sea. Mar Ecol Prog Ser 84:53-61

Nei M (1972) Genetic distance between populations. Am Nat 106:283-292
Oetinger DF, Nichol BB (1982) Developmental relationships between acanthocephalans and altered pigmentation in freshwater isopods. J Parasitol 68:463-469

Palumbi SR (1994) Genetic divergence, reproductive isolation, and marine speciation. Annu Rev Ecol Syst 25:547-572

Pérez-Portela R, Palacín C, Durán S, Turon X (2007) Biological traits of three closely related species of Pycnoclavella (Ascidiacea) in the western Mediterranean. Mar Biol 152: 1031-1038

Raymond M, Rousset F (1995) GENEPOP (Version 1.2) population genetic software for exact tests and ecumenicism. J Hered 86:248-249

Rodrigues SA, Rocha RM (1993) Littoral compound ascidians (Tunicata) from São Sebastião, Estado de São Paulo, Brazil. Proc Biol Soc Wash 106:728-739

Rodrigues SA, Rocha RM, Lotufo TMC (1998) Guia ilustrado para identificação das ascídias do Estado de São Paulo. IBUSP, FAPESP, São Paulo

Rooper CN, Haldorson LJ, Quinn TJ (1999) Habitat factors controlling Pacific herring (Clupea pallasi) egg loss in Prince William Sound, Alaska. Can J Fish Aquat Sci 56: 1133-1142

Sabbadin A, Graziani G (1967) Microgeographical and ecological distribution of colour morphs of Botryllus schlosseri (Ascidiacea). Nature 213:815-816

Schluter D (2001) Ecology and the origin of species. Trends Ecol Evol 16:372-380

Solé-Cava AM, Thorpe JP (1986) Genetic differentiation between morphotypes of the marine sponge Suberites fícus (Demospongiae: Hadromeida). Mar Biol 93:247-253

> Tarjuelo I, Posada D, Crandall KA, Pascual M, Turon X (2004) Phylogeography and speciation of colour morphs in the colonial ascidian Pseudodistoma crucigaster. Mol Ecol 13: 3125-3136

Tatarenkov A, Johannesson K (1994) Habitat related allozyme variation on a microgeographic scale in the marine snail Littorina mariae (Prosobranchia, Littorinacea). Biol J Linn Soc 53:105-125

> Thorpe JP (1982) The molecular clock hypothesis: biochemical evolution, genetic differentiation and systematics. Annu Rev Ecol Syst 13:139-168

Van Name WG (1945) The North and South American ascidians. Bull Am Mus Nat Hist 84:1-476

Weir BS, Cockerham CC (1984) Estimating F-statistics for the analysis of population structure. Evolution 38:1358-1370

Wicksten MK (1989) Why are there bright colors in sessile marine invertebrates? Bull Mar Sci 45:519-530

Yund PO, O'Neil PG (2000) Microgeographic genetic differentiation in a colonial ascidian (Botryllus schlosseri) population. Mar Biol 137:583-588 


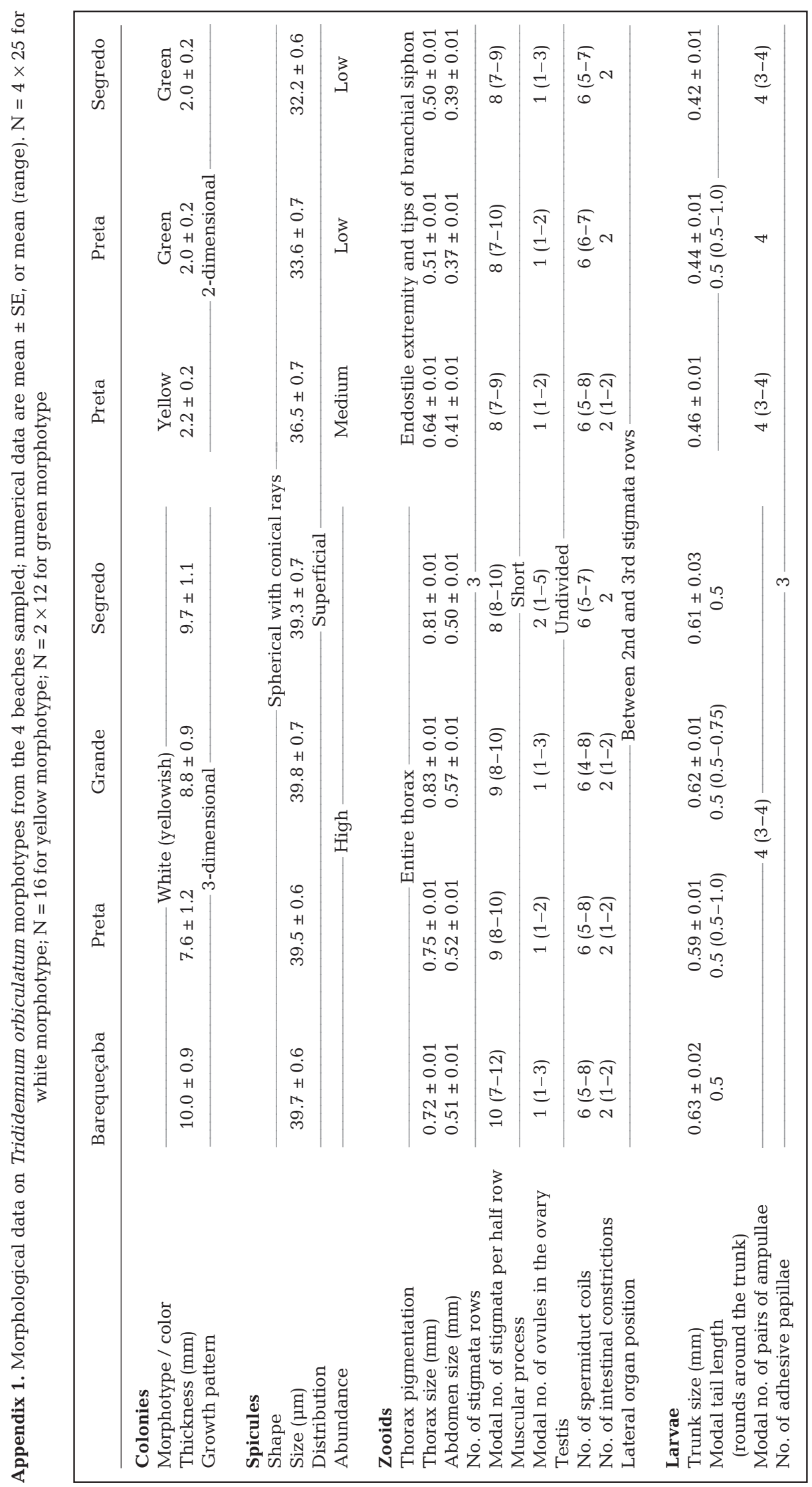

